\title{
Urban Runoff Pollutant Characteristics in Vientiane Capital, Lao PDR
}

\author{
Atsushi ICHIKI*, Vongsack MIXAY** \\ * Department of Environmental Systems Engineering, Ritsumeikan University, 1-1-1 \\ Nojihigashi, Kusatsu, Shiga 525-8577 Japan \\ ** Public Works and Transport Institute, Ministry of Public works and Transport of Lao PDR, \\ P.O. Box 5067, Dongpalane road, Vientiane Capital City, Lao PDR
}

\begin{abstract}
This study is highlighted to investigate the characteristics of pollutant runoff and relationships between pollutant load and runoff in an urban area of Vientiane city, Lao PDR. Hong Thong catchment area was selected for sampling during wet and dry weather. As a result of the survey, mean concentration of SS was higher in rainy season, in contrast, COD, TN and TP were much higher in dry season possibly due to being associated with domestic wastewater, and attenuation by stormwater in rainy season. The mean total PAHs concentration value were 230.13, 132.83 and $143.72 \mathrm{ng} / \mathrm{L}$ respectively for rainy season wet and dry periods, and dry season. Base on the composition of specific components, PAHs in Hong Thong catchment area was determined to be derived mainly from oil discharge rather than fuel combustion.
\end{abstract}

Keywords: urban water quality, PAHs, developing country, Vientiane.

\section{INTRODUCTION}

Urban runoff is one of the main important sources of pollution, which causes water quality deterioration with high pollutant loads including sediment, nutrients, heavy metals, oils and hydrocarbons, and oxygen demanding substances (US-EPA, 2002). There are complex relationships between runoff process and catchment characteristics during dry and wet weather periods. Therefore, the characterization of urban runoff pollutant is necessary for a water quality management in urban areas.

Polycyclic aromatic hydrocarbons (PAHs) are a class of diverse organic compounds containing two or more fused aromatic rings of carbon and hydrogen atoms. Anthropogenic input from incomplete combustion, oil spills, urban runoff, domestic and industrial wastewater discharges, as well as atmospheric fallout of vehicle exhaust and industrial stack emission have caused significant accumulation of these compounds in the environments (Zakaria, et al., 2002).

Inappropriate and inadequate drainage systems and sanitation is one of the major environmental problems facing unplanned urbanization in Vientiane Capital City, Lao PDR. The poor drainage of wastewater from septic tanks and poorly designed on-site sanitation has created a major concern for public health, causing widespread pollution of surface water and groundwater (Keosithamma, 2004). Most of sewage water together with stormwater is discharged directly into rivers and wetlands without any kind of treatment. The ongoing depletion of water quality has consequences not only on human but also on environmental health. However, little information is available on storm runoff pollution from urban areas in developing counties, including Lao PDR that

Address correspondence to Atsushi Ichiki, Department of Environmental Systems Engineering,

Ritsumeikan University, Email: a-ichiki@se.ritsumei.ac.jp

Received 19 December 2008, Accepted 13 June 2009 
highlights the significance of this study. The original objectives of this study are to survey changes of pollutants in runoff water from a core urban area, and to develop a predictive tool to obtain approximate pollutant loads from Vientiane City for the purpose of managing and improving drainage conditions in the city.

\section{STUDY METHODOLOGY}

The study area is situated in the central part of Vientiane capital urbanized area along the east bank of the Mekong River. The study catchments (Fig. 1) having an area of 205 ha with population of 14,674 (National Statistic Centre, 2005) can be categorized into two main land use type (residential and commercial areas) is considered as a sub-catchments of major tributaries of main drain channel (Hong Thong Channel), before discharging into That Luang Marsh which is connected to the downstream at Mekong River. The study area lies in a tropical region, with significant monsoon characteristics. The south-western monsoon causes rainfall from May until October as rainy season and dry season from November to April. The mean annual precipitation is approximately 1,700mm (Japan International Cooperation Agency, 2002).

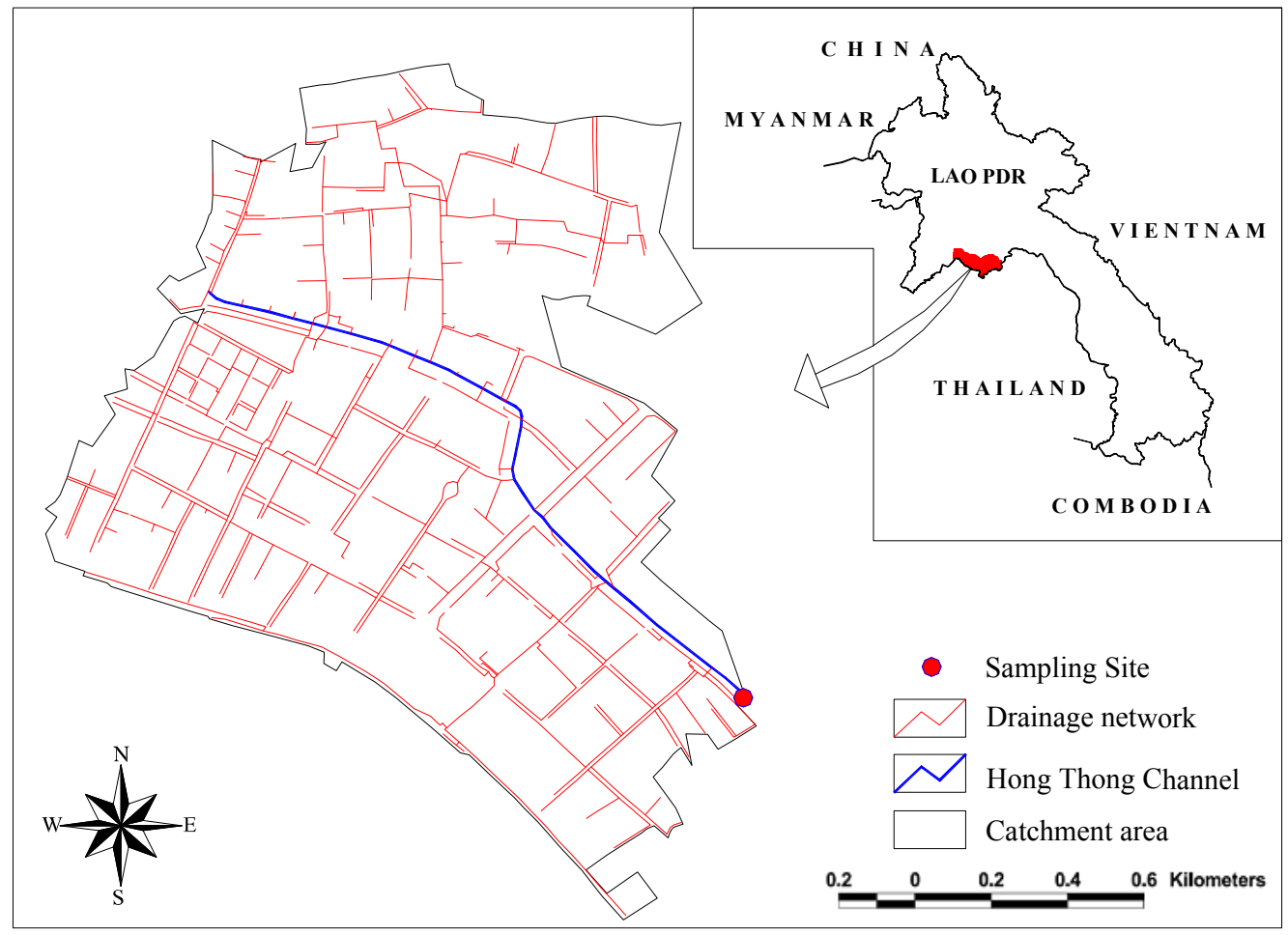

Fig. 1 - Outline of Study Area.

Five to twelve water samples per day were collected manually at the channel outlet during one week in rainy season, August 2007. And the discharge was continuously measured through rectangular weir by an automatic water level logger. Rainfall data was recorded by an automatic rain gauge near the sampling site. In addition, the same survey in dry season was also carried out in March 2008. All water samples were collected in plastic bottles and transported to laboratory for analysis in Japan. Suspended solids (SS), chemical oxygen demand (COD), total nitrogen (TN) and total 
phosphorus (TP) were measured according to standard methods (Japan Sewage Works Association, 1997), and PAHs were measured by GC-MS (Gas Chromatography/Mass Spectrometry) after extracted into dichloromethane according to US EPA Method 525.2 (USEPA National Exposure Research Laboratory; Ozaki et al., 2001).

The mean concentration of each constituent was determined as an event mean concentration (EMC). The EMC is a flow-weighted average of constituent concentration defined as total mass of pollutant contained in the runoff event divided by total volume of flow in the event (Novotny and Olem, 1994).

$$
E M C=\sum Q_{i} \cdot C_{i} / \sum Q_{i} \quad \text { eq. } 1
$$

Where, $Q_{i}$ is runoff flow $\left(\mathrm{m}^{3} / \mathrm{s}\right), C_{i}$ is concentration $(\mathrm{mg} / \mathrm{L})$ at a time $i$.

Pollutant load and runoff relationship is the increase in pollutant mass loading during storm and subsequent flow condition that is attributed to the nonpoint source effects. The load and runoff relationship can be shown in terms of eq. 2 .

$$
(L / A)_{n e t}=k \cdot(Q / A)_{n e t}{ }^{b} \quad \text { eq. } 2
$$

In which, $A$ is catchment area (ha), and $(L / A)_{n e t}$ and $(Q / A)_{n e t}$ are area specific runoff pollutant load $(\mathrm{kg} / \mathrm{ha})$ and flow $\left(\mathrm{m}^{3} / \mathrm{ha}\right)$ for a certain runoff period by storm minus base runoff load and flow. $k$ and $b$ are regression coefficients. The coefficients $k$ and $b$ are determined by a $\log$ transform of eq. 2 and liner regression. The coefficient $k$ means the base pollutant load, and $b$ means the runoff response of pollutants to storms.

\section{RESULTS AND DISCUSSION}

Fig. 2 shows the combining runoff volume and water quality data that produce hydrograph and pollutograph during rainy season (with $58.0 \mathrm{~mm}$ of precipitation) and dry season (with no rainfall). In rainy season, the pollutant concentration peak in the storm event is not clear. After the flow peak, the pollutant concentration rapidly reduced. As a whole, the rain pattern influenced the interval between the pollution peak and flow peak. The phenomena of first flush also did not clearly occurred for storm events monitored in Hong Thong catchments. Due to storm water quality was measured only the partial storm event, entire storm event might not be fully captured. This might underestimate event mean concentrations (EMCs) for each storm event in the following discussion.

Measured concentration ranges of SS, COD, TN and TP during storm events were 8.55-140.80 mg/L, 5.84-12.16 mg/L, 3.95-11.44 mg/L and 0.68-1.85 mg/L respectively. Mean concentration of SS was relatively low during low flow (dry day in rainy season and dry season) but was substantially higher during storm events due to increased runoff bringing particulate material into the channel, which indicates that those sediments in the catchments can freely move in response to runoff that more active by storm water. In contrast, concentration of COD, TN and TP were greater in dry season than in rainy season. The behavior and seasonal variation of COD was quite similar to TN and TP in both season. Therefore, possibly due to the attenuation by rainwater, which is inferred a large component of COD, TN and TP is derived from the same source and associated with domestic wastewater. Summary of the water quality is shown in Table 1. 

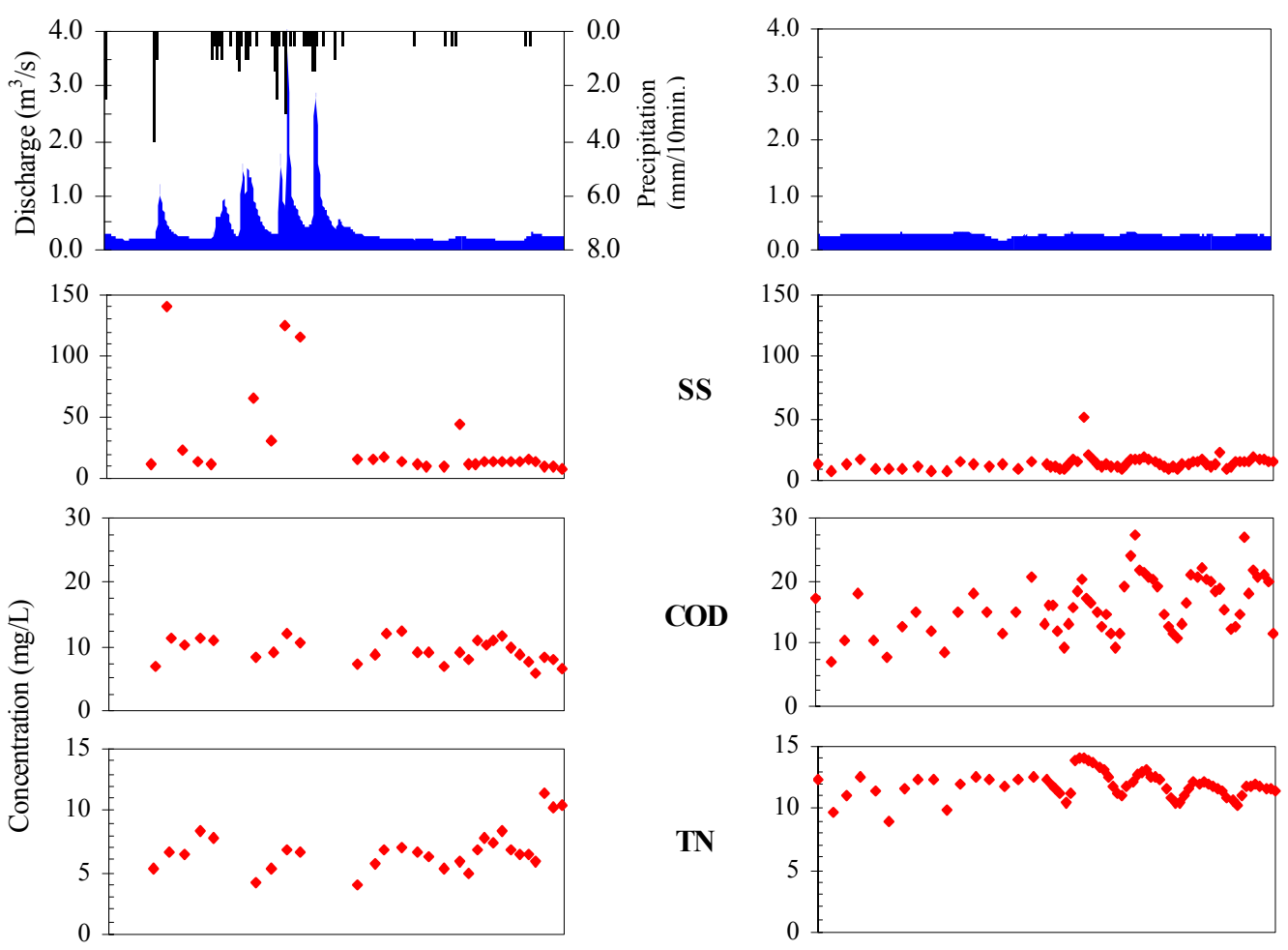

SS

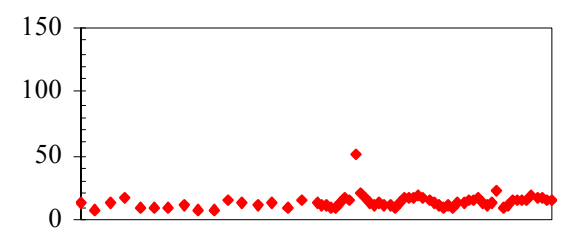

COD

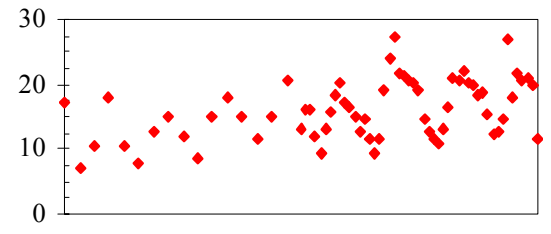

TN
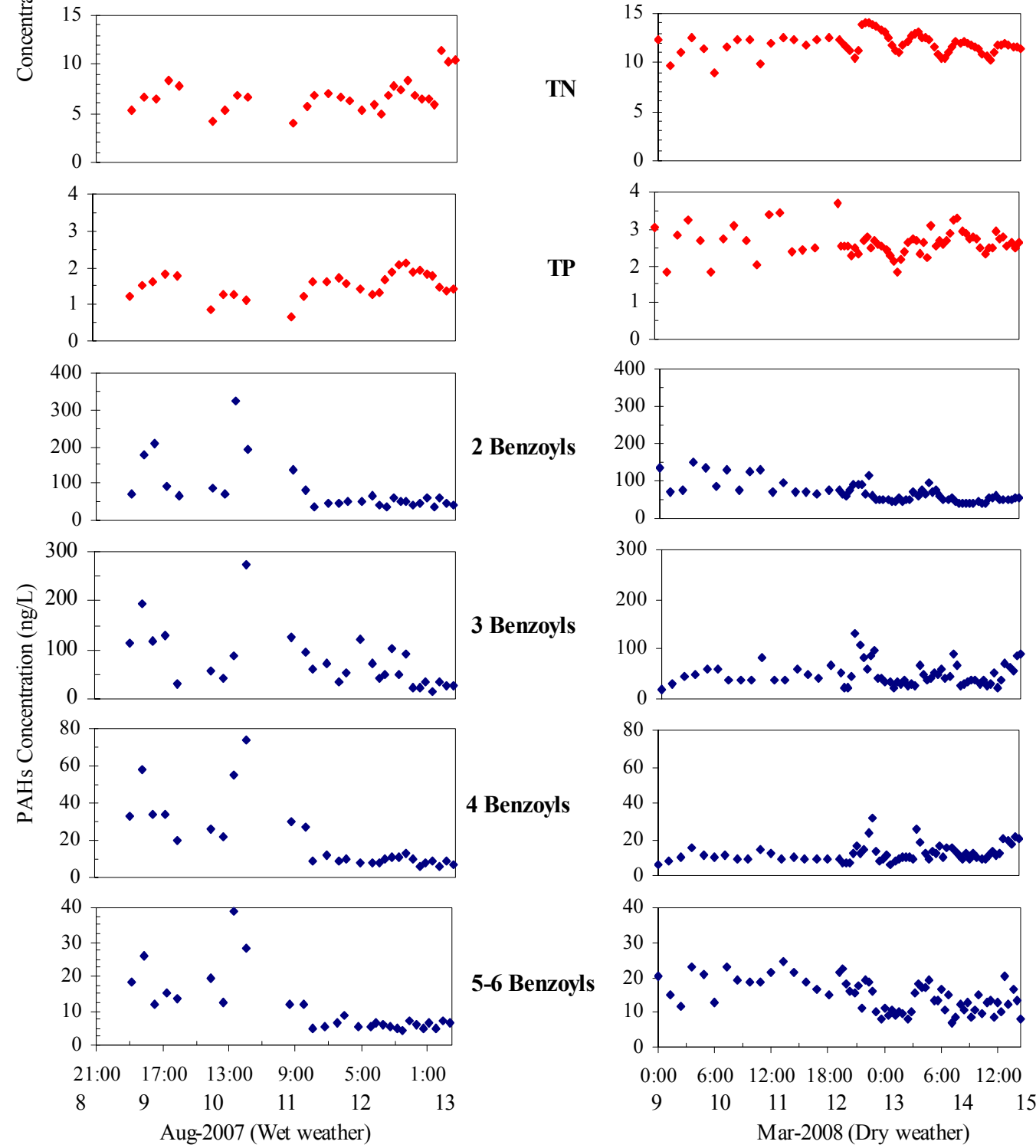

Fig. 2 - Variation of Discharge and Concentration of SS, COD, TN, TP and PAHs. 
Table 1 - EMC for Dry and Wet Weather Events.

\begin{tabular}{|c|c|c|c|}
\hline Season & \multicolumn{2}{|c|}{ Rainy } & Dry \\
\hline Weather & Wet & Dry & Dry \\
\hline \multirow{3}{*}{ SS } & 140.80 & 14.30 & 51.25 \\
\hline & 60.04 & 12.25 & 14.77 \\
\hline & 8.55 & 10.05 & 6.75 \\
\hline \multirow{3}{*}{ COD } & 12.16 & 12.36 & 27.45 \\
\hline & 9.43 & 9.87 & 16.27 \\
\hline & 5.84 & 6.99 & 7.03 \\
\hline \multirow{3}{*}{$\mathrm{TN}$} & 11.44 & 8.40 & 14.37 \\
\hline & 6.44 & 6.84 & 12.55 \\
\hline & 3.95 & 5.26 & 8.97 \\
\hline \multirow{3}{*}{ TP } & 1.85 & 2.13 & 4.19 \\
\hline & 1.29 & 1.74 & 2.66 \\
\hline & 0.68 & 1.21 & 1.81 \\
\hline
\end{tabular}

Upper: max., Middle: mean, Lower: min. (unit:mg/L)

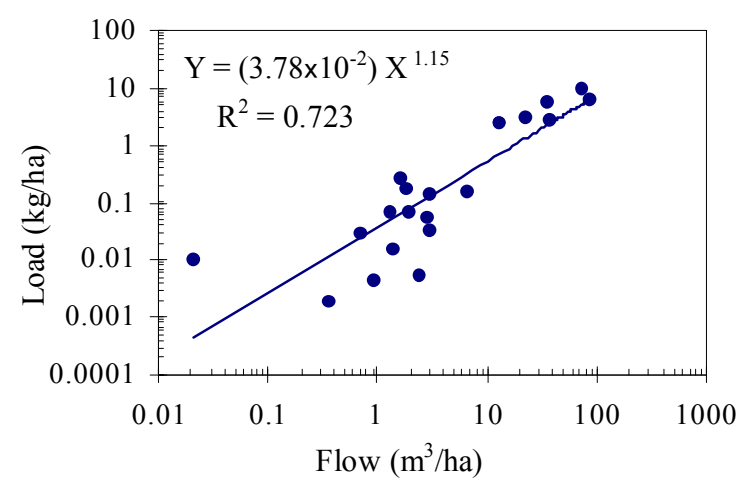

(a) $\mathrm{SS}$

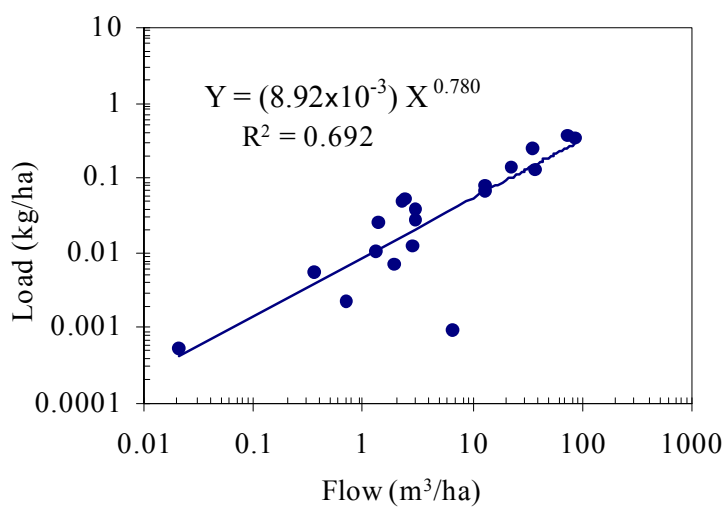

(c) $\mathrm{TN}$

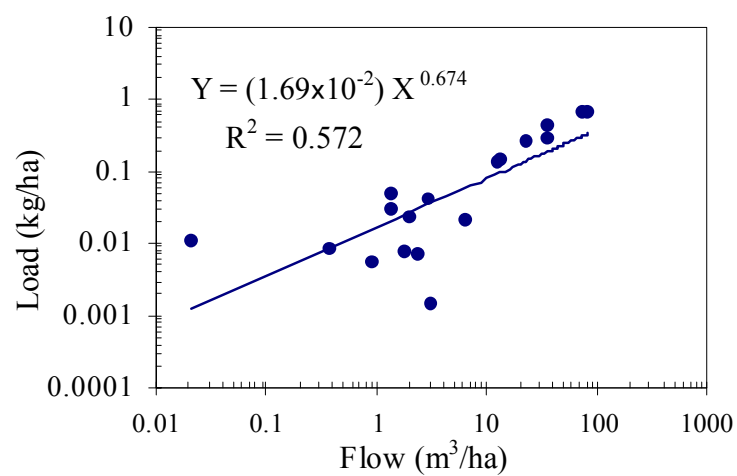

(b) COD

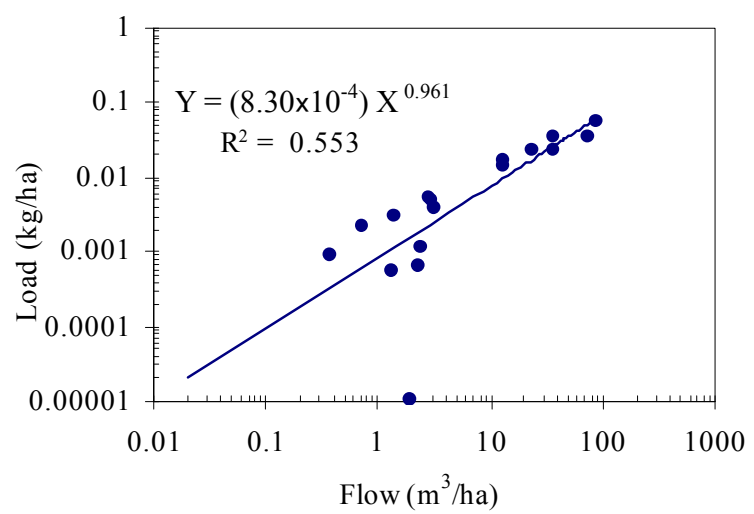

(d) TP

Fig. 3 - Relationship between Runoff Pollutant Load and Flow by Storm. 
Fig. 3 shows the result of regression analysis for SS, COD, TN and TP between runoff load and flow for selected constituents from catchments during the storm events. The base pollutant load coefficient $k$ are $3.78 \times 10^{-2}$ for SS, $1.69 \times 10^{-2}$ for COD, $8.92 \times 10^{-3}$ for TN and $8.30 \times 10^{-4}$ for TP, while the runoff response to storm events $b$ are 1.15 for SS, 0.674 for COD, 0.780 for TN and 0.961 for TP respectively. The base pollutant load coefficient $k$ which show potential pollutant loads in the catchment are relatively large. And the runoff response to storm events $b$ are larger in solid pollutants than in soluble pollutants.

Table 2 illustrates the concentration ranges and individual of PAHs compounds in water samples in different weathers, and the variation of PAHs concentration with each benzoyls are shown in Fig. 2. The detected concentrations in water ranged between 0.13-311.31 ng/L for wet weather period in rainy season, $0.11-91.6 \mathrm{ng} / \mathrm{L}$ for dry period in rainy season and $0.09-145.93 \mathrm{ng} / \mathrm{L}$ for dry season with the mean total PAHs concentration value of $230.13 \mathrm{ng} / \mathrm{L}, 132.83 \mathrm{ng} / \mathrm{L}$ and $143.72 \mathrm{ng} / \mathrm{L}$ respectively for each period/season. Generally, total PAHs concentration in rainy season is higher than in dry season, this implies that PAHs concentration is more influenced by the storm runoff during rainy season. The sorption of PAHs onto suspended solids in water may be the main contributive factor for the high PAHs concentrations in rainy season.

The composition pattern of PAHs with benzoyl parts is presented in Fig. 4. The PAHs concentration was mainly dominated by 2 and 3 bezoyls in both seasons. Main compound in the PAHs is naphthalene for 2 benzoyls, phenanthrene for 3 benzoyls, pyrene for 4 benzoyls and benzo(a)pyrene for 5-6 benzoyls. The most abundant unsubstantiated individual compounds were naphthalene and phenanthrene. The percentage of the various PAHs provides information regarding possible source of the chemicals, as well as the potential for the components of the mixture to cause adverse health problems. The results in Fig. 4 compare the percentage of the various PAHs compounds. More than $80 \%$ of all samples collected in storm events, base flow in rainy and dry season were the smaller ( 2 and 3 benzolys) PAHs. These compounds are generally less toxic and more susceptible to degradation. The lager (4-6 benzolys) compounds were less than $20 \%$ of the total PAHs. These compounds are both more persistent in environment and human carcinogens. The complex mixtures of PAHs associated with environmental pollution can be classified into two main categories depending on the process of their formation. Petrogenic PAHs originated from fossil fuels such as petroleum and coal. These PAHs are formed over long periods of time at moderate temperatures. Petrogenic PAHs mixtures are generally rich in the lower molecular weight PAHs ( 2 or 3 benzoyls). Pyrogenic PAHs are presented in the products of incomplete combustion of biomass and fossil fuels. Pyrogenic PAHs are formed at high temperatures and are generally enriched in higher molecular weight PAHs (4-6 bezoyls). The PAHs detected in water samples from Hong Thong catchment area to originate primarily from petrogenic sources. Concentrations of the low molecular weight PAHs were generally more than $80 \%$ of the total PAHs, while the high molecular weight PAHs accounted for less than $10 \%$ of total PAHs. The profiles of these PAHs showed a possibility that the PAHs derived mainly from oil discharge rather than fuel combustion. 
Table 2 - Summary of PAHs EMCs (unit: ng/L).

\begin{tabular}{|c|c|c|c|c|}
\hline \multirow{2}{*}{$\begin{array}{l}n \\
\grave{2} \\
\stackrel{0}{N} \\
\overrightarrow{0} \\
\infty\end{array}$} & \multirow{2}{*}{ Parameter } & \multicolumn{2}{|c|}{ Rainy season } & \multirow{2}{*}{$\frac{\text { Dry s. }}{\text { Dry }}$} \\
\hline & & Wet & Dry & \\
\hline \multirow{12}{*}{2} & \multirow{3}{*}{$\begin{array}{l}\text { Naphthalene } \\
\text { (NAP) }\end{array}$} & 311.31 & 63.95 & 145.93 \\
\hline & & 95.28 & 44.80 & 62.86 \\
\hline & & 29.39 & 33.22 & 35.13 \\
\hline & \multirow{3}{*}{$\begin{array}{l}\text { Acenaphthy rene } \\
\text { (AYL) }\end{array}$} & 4.71 & 2.60 & 1.73 \\
\hline & & 1.70 & 0.90 & 0.50 \\
\hline & & 0.31 & 0.42 & 0.09 \\
\hline & \multirow{3}{*}{$\begin{array}{l}\text { Acenaphthene } \\
\text { (AEN) }\end{array}$} & 13.89 & 10.48 & 20.98 \\
\hline & & 6.54 & 5.25 & 4.51 \\
\hline & & 2.63 & 2.74 & 1.38 \\
\hline & \multirow{3}{*}{$\begin{array}{l}\text { Fluorene } \\
\text { (FRE) }\end{array}$} & 32.17 & 13.50 & 14.37 \\
\hline & & 10.40 & 6.33 & 4.11 \\
\hline & & 2.69 & 3.34 & 1.33 \\
\hline \multirow{9}{*}{3} & \multirow{3}{*}{$\begin{array}{l}\text { Phenanthrene } \\
\text { (PHE) }\end{array}$} & 186.08 & 91.60 & 90.74 \\
\hline & & 57.13 & 45.21 & 30.29 \\
\hline & & 9.72 & 15.07 & 11.87 \\
\hline & \multirow{3}{*}{$\begin{array}{l}\text { Anthracene } \\
\qquad(\mathrm{ANT})\end{array}$} & 11.15 & 9.37 & 10.23 \\
\hline & & 3.66 & 3.71 & 2.93 \\
\hline & & 0.70 & 0.75 & 0.43 \\
\hline & \multirow{3}{*}{$\begin{array}{l}\text { Fluoranthene } \\
\text { (FLU) }\end{array}$} & 45.29 & 18.80 & 29.43 \\
\hline & & 13.21 & 8.07 & 11.52 \\
\hline & & 1.87 & 2.34 & 3.15 \\
\hline \multirow{15}{*}{4} & \multirow{3}{*}{$\begin{array}{l}\text { Pyrene } \\
\text { (PYR) }\end{array}$} & 38.46 & 16.83 & 22.4 \\
\hline & & 12.30 & 6.41 & 8.5 \\
\hline & & 2.11 & 2.92 & 4.2 \\
\hline & \multirow{3}{*}{$\begin{array}{c}\text { Chry sene+T ripheny lene } \\
\text { (CRS+TPL) }\end{array}$} & 2.72 & 1.15 & 2.0 \\
\hline & & 0.75 & 0.40 & 0.6 \\
\hline & & 0.13 & 0.11 & 0.2 \\
\hline & \multirow{3}{*}{$\begin{array}{c}\text { Benzo(a)anthracene } \\
(\mathrm{BaA})\end{array}$} & 7.52 & 3.86 & 2.5 \\
\hline & & 1.98 & 0.93 & 0.9 \\
\hline & & 0.38 & 0.36 & 0.2 \\
\hline & & 23.02 & 10.71 & 5.1 \\
\hline & $\begin{array}{l}\text { Benzo(k)iluorantnene } \\
\text { (BkF) }\end{array}$ & 8.11 & 4.32 & 2.0 \\
\hline & & 2.01 & 1.02 & 0.4 \\
\hline & Benzo(b)fluoranthene & 6.10 & 1.70 & 1.4 \\
\hline & Benzo(b)fluoranthene & 1.73 & 0.73 & 0.4 \\
\hline & & 0.27 & 0.34 & 0.2 \\
\hline & & 18.32 & 8.84 & 16.7 \\
\hline & Benzo(a)p y rene & 4.39 & 2.28 & 7.9 \\
\hline & & 0.62 & 0.35 & 1.4 \\
\hline & & 5.80 & 1.70 & 2.8 \\
\hline & Benzo(e)pyrene & 1.61 & 0.77 & 1.0 \\
\hline & & 0.31 & 0.24 & 0.3 \\
\hline & & 3.44 & 1.34 & 4.7 \\
\hline 5 & Peryiene & 1.19 & 0.69 & 2.0 \\
\hline & & 0.34 & 0.25 & 0.8 \\
\hline & & 5.06 & 1.60 & 1.8 \\
\hline & Indeno( $1,2,3-\mathrm{cd})$ py rene & 1.72 & 1.23 & 1.3 \\
\hline & & 0.49 & 0.65 & 0.7 \\
\hline & & 3.70 & 2.10 & 1.5 \\
\hline & Dibenzo(a,h)anthracene & 1.47 & 1.10 & 1.01 \\
\hline & & 0.49 & 0.60 & 0.6 \\
\hline & & 8.80 & 4.31 & 3.6 \\
\hline 6 & Benzo(g,n,I)pery rene & 2.69 & 1.66 & 1.47 \\
\hline & & 1.01 & 0.91 & 0.7 \\
\hline & Total PAHs & 230.13 & 132.83 & 143.72 \\
\hline
\end{tabular}

Upper: max., Middle: mean, Lower: $\min$. 


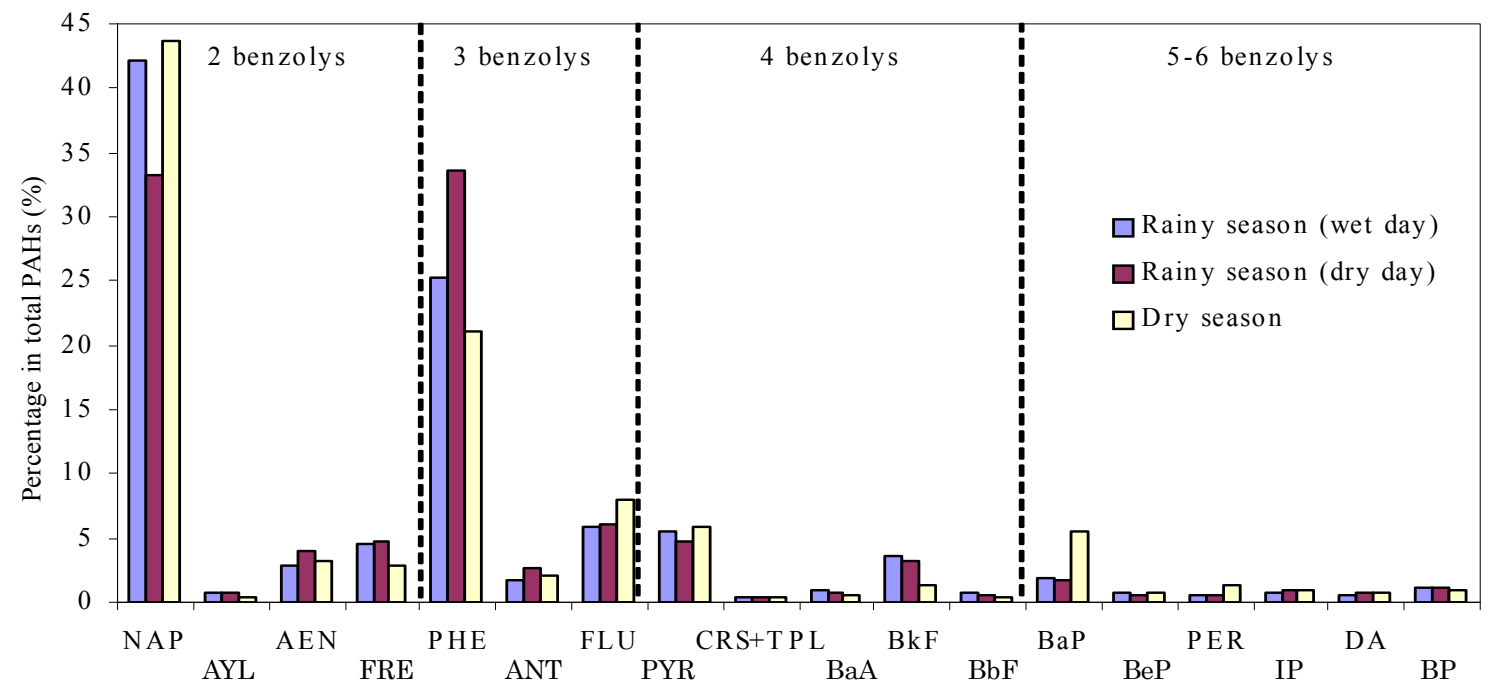

Fig. 4 - PAHs Profile.

\section{CONCLUSIONS}

The results of this study confirm that water quality indicator of COD, TN and TP contained high concentration in dry season these compounds mainly came from domestic wastewater, and lower in rainy season due to attenuated by storm water. However, SS concentration substantially increased during storm events in response to runoff. The results coupled with investigation of appropriate PAHs allowed identification of the primary PAHs source from oil discharge rather than fuel combustion. It shows unique results especially in developing countries compared with the characteristics in developed countries (Ichiki, et al., 2008). This initial study provided useful information for the evaluation of water quality and will guide future efforts to identify ways to reduce urban runoff pollutants exposures and ultimately to reduce risk in Vientiane City, Lao PDR.

\section{ACKNOWLEDGEMENT}

This research was partially supported by the Ministry of Education, Science and Culture in Japan, Grant-in-Aid for Scientific Research (C), 19560553, 2007-2009. The authors would like to thank their colleagues for their precious efforts to carry out this research. Especially, Prof. Kiyoshi Yamada formerly in Ritsumeikan University gave them many pieces of available advice and suggestions.

\section{REFERENCES}

Ichiki, A., Ido, F. and Minami, T. (2008). Runoff characteristics of highway pollutants based on a long-term survey through a year, Water Science and Technology, 57(11), 1769-1776.

Japan International Cooperation Agency (2002). The Survey on Existing Road and Drainage Condition in Vientiane Municipality of Project, JICA.

Japan Sewage Works Association (1997). Standard Methods of SeTest, Japan Sewage Works Association (in Japanese). 
Keosithamma, B. (2004). Urban Environmental Sanitation Improvements in Vientiane. Proceedings of the 30th Water Engineering Development Centre Conference, Vientiane, Lao PDR, 100-103.

National Exposure Research Laboratory, Office of Research and Development, U.S. Environmental Protection Agency, Method 525.2 Determination of Organic Compounds in Drinking Water by Liquid-Solid Extraction and Capillary Column Gas Chromatography / Mass Spectrometry, Revison 2.0.

National Statistic Centre (2005). Population census 2005, Committee for Planning and Cooperation, Vientiane, Lao PDR.

Novotny V. and Olem H. 1994. Water Quality - Prevention, Identification and Management of Diffuse Pollution, Van Nostrand Reinhold, New York.

Ozaki N., Ganda T., Fukushima T. and Kamatsu T. (2001). Atmospheric deposition of PAHs on urban area and their runoff, CD of Proc. 5th Int. Conf. on Diffuse/Nonpoint Pollution and Watershed Management, Milwaukee.

US-EPA (2002). 2000 National water quality inventory [R], Office of Water, Washington DC. http://www.epa.gov/305b/2000report.

Zakaria MP, Takada H, Tsutsumi S, Ohno K, Yamada J, Kouno E, Kumata H. (2002). Distribution of polycyclic aromatic hydrocarbons (PAHs) in rivers and estuaries in Malaysia: a widespread input of petrogenic PAHs. Environ. Sci. Technol., 36, $1907-1918$. 